\title{
Imigrantes italianos no Brasil meridional: práticas sociais e culturais na conformação das comunidades coloniais
}

\author{
Italian immigrants in southern Brazil: \\ social and cultural practices in the configuration \\ of colonial communities
}

\author{
Inmigrantes italianos en el Brasil meridional: \\ prácticas sociales y culturales en la conformación \\ de las comunidades coloniales
}

\begin{abstract}
Resumo: O presente artigo pretende trazer elementos para avançar no entendimento da sociedade rural italiana formada no Rio Grande do Sul a partir do final do século XIX. Na percepção dos imigrantes, o espaço que compreendia os núcleos coloniais se caracterizava enquanto local de vivência de costumes, devendo ser gerenciado por normas próprias de controle. O contato conflituoso entre imigrantes e brasileiros permite perceber a maneira como os europeus compreendiam o território colonial. Palavras-chave: Imigração italiana. Rio Grande do Sul. Comunidades coloniais.
\end{abstract}

Abstract: This article aims to bring elements to enhance the understanding of Italian rural society formed in Rio Grande do Sul from the late nineteenth century. The perception of immigrants, the space comprised the colonial nuclei was characterized as a place of living of customs and shall be managed by its own standards of control. The conflictual contact between immigrants and Brazilians allows realize how Europeans understood the colonial territory.

Keywords: Italian Immigration. Rio Grande do Sul. Colonial communities.

Resumen: El presente texto busca traer elementos para avanzar la comprensión de la sociedad rural italiana que se formó en la provincia del Rio Grande do Sul, a partir de los finales del siglo XIX. En la percepción de los inmigrantes, el espacio

\footnotetext{
${ }^{\text {a }}$ Doutora em História PUCRS. Bolsista do Programa Nacional de Pós-Doutorado da Coordenação de Aperfeiçoamento de pessoal de Nível Superior (PNPD/CAPES). Professora colaboradora do Programa de Pós-Graduação em História da Universidade Federal de Santa Maria.

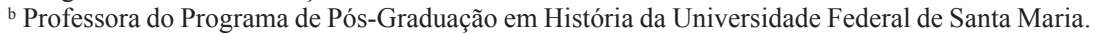


formado por las nucleaciones coloniales se caracterizaba como local de vivir las costumbres, debiendo tener normas propias de control. El contacto conflictivo entre inmigrantes y brasileños nos ha permitido percibir la manera como los europeos comprendían al territorio colonial.

Palabras clave: Inmigración italiana. Rio Grande do Sul. Comunidades coloniales.

\section{Introdução}

Os grupos de imigrantes italianos que começaram a chegar à região central do Rio Grande do Sul, a partir do final de 1877, eram, na sua maior parte, compostos por camponeses, alguns pequenos proprietários, que buscavam manter seu modo de vida por meio da obtenção de terras e reconstrução de novas comunidades no lugar de instalação. Trata-se de uma imigração familiar, de população oriunda do norte da Itália e, em sua maioria, católica. A existência de uma articulação pretérita entre algumas famílias, especialmente devido às origens comuns dos paesi (localidades) italianos, foi um aspecto que favoreceu a concretização de pretensões coletivas do grupo. Esta experiência permitiu a ocupação conjunta de determinados espaços, a formação de unidades coorporativas através da parentela e vizinhança e a posterior fundação das comunidades por famílias interligadas por vínculos de parentesco, afinidade, amizade e interdependência.

Neste artigo, inicialmente abordar-se-á o deslocamento de um grupo de emigrantes da Província de Treviso, região do Vêneto, para o sul do Brasil. À frente do agregado de famílias se encontrava o camponês Paulo Bortoluzzi. O estabelecimento num mesmo núcleo de ocupação, o estabelecimento de uma cadeia migratória, unindo o lugar de destino àquele de partida e a existência de vínculos entre os imigrantes, permitiu a fundação de comunidades. Essas são fruto da vivência de uma cultura do auxílio, assistência e solidariedade entre vizinhos, parentes e conhecidos, possibilitando a formação de pequenas unidades corporativas.

Alguns indivíduos assumiram papel de destaque na organização dos espaços de sociabilidade e estruturação dos povoados, mediante a vivência de práticas religiosas e edificação de símbolos que permitiam agregação, identificação e também a construção de paisagens culturais em que a religiosidade católica ocupava um papel de destaque (Zanini, 2008). Na percepção dos imigrantes, o espaço que compreendia 
a Colônia e os núcleos coloniais se caracterizava enquanto local de vivência de costumes e de práticas sócio-religiosas. Essa compreensão orientava atitudes de controle e superioridade em relação aos indivíduos de origem étnica diversa quando em processos interativos comuns, como no caso dos nativos e habitantes da região, que foram denominados de brasileiros. A distinção baseada na origem diversa se observava quando estes compareciam nos espaços de sociabilidade ocupados pelos italianos no centro do povoado ou quando os imigrantes se dirigiam aos centros urbanos próximos. Aos domingos, após as celebrações religiosas, eram nas casas de comércio que os imigrantes se encontravam, e, naqueles lugares, surgiam conflitos entre italianos e brasileiros. Geralmente, esses sempre saíam em desvantagens, principalmente por serem aqueles a maioria e também por causa da força da solidariedade étnica. A análise de alguns processos-crime permitirá perceber os momentos em que era reforçada a existência de uma solidariedade étnica e estabelecidas diferenciações entre os grupos nos núcleos de colonização italiana.

\section{Redes sociais}

As famílias camponesas que passaram a imigrar para o Rio Grande do Sul ao final do século XIX saíram do norte da península Itálica, especialmente da região do Vêneto. Nas províncias de origem, as populações do campo se reuniam em pequenas comunidades rurais nas quais possuíam seus símbolos de agregação e identificação. A existência de uma diversidade cultural entre os grupos que povoavam o território italiano se manifestava por meio da variedade de línguas faladas em diferentes espaços, das devoções a santos distintos, da culinária e também pelas rivalidades entre paesi ${ }^{1}$. As especificidades locais também podiam ser visualizadas em determinadas devoções e associações religiosas vivenciadas nas comunidades. Quando do deslocamento para a América, formou-se em alguns povoados grupos de famílias que, unidas, decidiram pela transferência coletiva, pois, assim, acreditavam poder contar com maior segurança para garantir a efetivação dos projetos individuais e coletivos (Vendrame, 2013). A existência de coesão comunitária, enquanto característica da cultura camponesa, contribuiu para que os deslocamentos transoceânicas ocorressem com a participação ativa de agregados parentais e vizinhos. Um exemplo disso

\footnotetext{
${ }^{1}$ Segundo Maria Maciel (1996, p. 34-35), para se medir o tamanho dessa diversidade basta considerar que, na época da Unificação, em 1860, a língua italiana era falada por menos de 3\% da população.
} 
pode ser percebido a partir das escolhas de um grupo de imigrantes que, em 1877, deixou a comuna de Piavon - Província de Treviso - para fundar uma nova comunidade no sul do Brasil. Não se pode esquecer, igualmente, o papel desempenhado pelos religiosos que se convertiam em agentes de imigração (Lorenzoni, 1975; Vendrame, 2013) e da Igreja católica que finda por migrar junto com aquelas populações, estabelecendo uma série de congregações no sul do Brasil.

O imigrante Paulo Bortoluzzi foi um dos principais articuladores da travessia, tendo reunido mais de duzentas pessoas entre parentes e amigos das localidades vizinhas para emigrar. Faziam parte do grupo pequenos proprietários e arrendatários que dispunham de certo patrimônio material, vendendo, antes de partir, os bens que possuíam (Vendrame, 2013, p. 83-123). A ampla adesão à emigração na comuna de Piavon e locais vizinhos foi explicada por contemporâneos como fruto da existência de uma "corrente de excitação" religiosa promovida pelos indivíduos pertencentes à ordem dos terciários franciscanos, já que tanto Bortoluzzi como outros que o acompanhavam faziam parte da dita irmandade religiosa. Desse modo, foram descritos como um grupo de "fanáticos", "ambiciosos" e "ignorantes", mas não miseráveis ou desocupados que estavam fugindo do campo pela falta de alimentos e recursos materiais que impediam a sobrevivência ${ }^{2}$. O que interessa destacar, para além das expectativas dos camponeses que queriam garantir para suas famílias estabilidade econômica e construir um patrimônio material, é a vontade de poder reviver as práticas e crenças religiosas em terras distantes.

Durante todo o ano de 1877, o camponês Bortoluzzi trabalhou para organizar a transferência do grupo, expressando seu desejo individual de se tornar "chefe de uma colônia no Brasil"3. Para tanto, partiu com a quantia de 12.000 liras em papel moeda, valor esse significativo na opinião do senador italiano Luiz Revedin. Bortoluzzi não foi descrito como um camponês miserável, já que era um pequeno proprietário, arrendatário e criador de animais. As opções adotadas por alguns, como as do referido camponês, funcionaram como um estímulo aos demais, fazendo com que rapidamente vendessem os bens para investir na aquisição de novas terras do outro lado do Atlântico ${ }^{4}$.

\footnotetext{
${ }^{2}$ Resposta do conde Luiz Revedin, Questionário do Ateneo di Treviso, 3 fevereiro 1878; Relação final do Ateneo de Treviso, Luiz Bailo, 1878, Pasta 13, fascículo 2, Arquivo Comunal de Treviso - Biblioteca Borgo Cavour (ACTV).

${ }^{3}$ Resposta de Luiz Revedin, 1878, Pasta 13, fascículo 2, ACTV.

${ }^{4}$ Para saber mais das iniciativas e negociações realizadas pela família de Paulo Bortoluzzi antes de abandonar a Província de Treviso, ver: Vendrame, 2013.
} 
Assim, em 1878, após chegarem à região colonial localizada no centro do Estado do Rio Grande do Sul - a denominada Colônia Silveira Martins -, o grupo imigrante liderado por Bortoluzzi fundou uma pequena comunidade que, posteriormente, passou a se chamar Vale Vêneto. Neste local, Paulo Bortoluzzi adquiriu diversos lotes coloniais, abriu uma casa de negócio e um moinho. Ao mesmo tempo, foi edificada pelos chefes de família uma pequena capela, sendo nomeado como padroeiro São Francisco de Assis porque entre os imigrantes existiam membros da Ordem Terceira de São Francisco (Ceretta, 1894, p. 24). Uma imagem do referido santo que havia sido trazida pelos italianos foi colocada na igreja edifica. A devoção a São Francisco de Assis e os objetos que o representavam surgem, então, como elementos simbólicos de identificação entre os indivíduos que tinham partido conjuntamente da comuna de Piavon e outras comunas vizinhas.

A presença de devoções e dialetos específicos, certamente foram aspectos que contribuíram decisivamente para reforçar ou criar novos vínculos de solidariedade e identificação entre determinados grupos. O estabelecimento de indivíduos da Província de Udine no centro do Rio Grande do Sul fez com que esses fossem identificados pelos conterrâneos italianos como "furlani" (ou "friulani"), uma vez que falavam um dialeto característico do local de origem, segundo afirmou o padre Francisco Burmann (1910, p. 21). As características regionais forneceram elementos para as classificações e divisões internas na região colonial e de modo geral entre os imigrantes, bem como viabilizaram a formação de lugares com presença significativa de famílias de uma mesma região da Itália. A toponímia de algumas comunidades indicam a origem dos indivíduos, como as comunidades de Novo Treviso, Vale Veronês, Vale Vêneto, Polêsine, dentre outras.

À medida que os imigrantes chegavam à Colônia Silveira Martins ${ }^{5}$ foi se formando uma rede de pequenos povoados partindo do estabelecimento de amplos agregados familiares que mantinham laços de parentesco. Nesse sentido, a instalação das famílias coligadas por vínculos parentais, de vizinhança e amizade demonstram que as relações de afinidade pretéritas ditaram os contornos iniciais da fundação da nova unidade territorial. A base de integração nos locais de recepção era formada por grupos de famílias unidas por ligações especiais, um dos princípios básicos que fundamentava o próprio direito de constituição

\footnotetext{
${ }^{5}$ Silveira Martins era a Sede da colônia italiana que abrangia ainda outros nascentes povoados no centro da província. Foi uma homenagem prestada ao político liberal sul-rio-grandense de marcante atuação no Senado Imperial. Com o advento da República, em 1889, o nome foi preservado.
} 
da comunidade. Desse modo, o novo espaço se estruturou como se fosse um prolongamento daquele que foi deixado para trás na pátria de origem. Essa questão encontra sua explicação, principalmente, na maneira como ocorreu a ocupação pelos imigrantes dos núcleos coloniais. Há famílias que mantém os vínculos de afinidade até os dias atuais, criando certo parentesco promovido pela experiência migratória, pelo qual diferentes gerações se percebem interligadas por relações de solidariedade, respeito e ajuda mútua (Zanini, 2006).

A constituição do Vale Vêneto exemplifica a relação direta existente entre o ambiente de origem e o de adoção, uma vez que as famílias se organizaram partindo dos laços que uniam indivíduos que já se conheciam. Os vínculos ativados quando da instalação na sociedade de destino também são guias para se entender alguns dos princípios que proporcionaram o surgimento de configurações sociais sólidas, a formação de centros de agregação e identificação cultural entre os imigrantes. Assim, se por um lado, a formação da localidade composta por cadeias migratórias pode se tornar uma barreira nas relações com a nova sociedade, por outro, pode se transformar em canais de acomodação e integração (Ramella, 1991, p. 113-114).

Alguns imigrantes, como Paulo Bortoluzzi, não eram totalmente pobres, deslocando-se com capital ser investido no lugar de instalação. Depois de algum tempo, passaram a favorecer os parentes e conhecidos que haviam permanecido na Itália financiando as viagens para o Brasil e os acomodando satisfatoriamente. A garantia de assistência na chegada, de financiamento da transferência, da hospedagem e de subsídios nos primeiros tempos, certamente foi um fator que permitiu a emigração em cadeia. Isso pode ser percebido no exemplo que será apresentando na sequência.

Em novembro de 1878, da comuna de Gemona, província de Udine, o padre Pedro Forgiarini, a pedido de um paroquiano, encaminhou uma carta ao conterrâneo Pedro Londero que se encontrava na Colônia Silveira Martins, no qual afirmava:

Das vossas cartas que aqui chegaram, se vem saber que a vossa posição no Brasil é boa e que estão bem colocados. Por causa disso aqui está nascendo o desejo de imigrar àquelas colônias [Silveira Martins], que dão mais condições e que aqui na Itália não há; mas faltam meios para fazer esta longa viagem. Se vocês ou outros, porque são pessoas cristãs, se encontram em condições de ajudar alguns e de hospedá-los no total ou em parte, para fazer a viagem, certo que estes vos serão muitos gratos, como podeis imaginá-lo. 
Na função de mediador, o padre Forgiarini solicitava auxílio em nome de Gerolamo Brondani - esposa e filhos - para que, assim, pudessem se juntar aos parentes e conhecidos que já se encontravam no núcleo colonial. Apresentava todos os indivíduos que compunham o grupo que necessitavam de ajuda ${ }^{6}$. Consequentemente, esse comportamento recriava um sistema de clientela e dependência entre as famílias nas novas comunidades. Tanto a troca de informações quanto o fornecimento de assistência nos núcleos coloniais ocorriam por meio de uma fina rede de ligações que permitiam o fornecimento de auxílios aos recém-chegados.

Assim, entende-se que a ideia da mobilidade para as regiões coloniais era aceita e estimulada, principalmente pelo recebimento de notícias pela circulação de cartas. As correspondências surgem, então, como mecanismo que permitiu a formação de canais espontâneos de transferência para o além-mar ${ }^{7}$. Os planos em relação à emigração, para muitos, desenvolveram-se desde a sequência de iniciativas organizadas entre o ambiente social de origem e o local de recepção. Tanto nos povoados de partida como nos de recepção, os camponeses se encontravam imersos em relações diversas - horizontais, verticais, intensas e frequentes - não podendo, por isso, serem vistos como um grupo isolado. O capital relacional e os recursos disponíveis para cada um diferia em tom e intensidade, mas a utilização destes mecanismos pode ser explicada a partir da análise de experiências particulares (Miguez, 1995).

Constatou-se que, em novembro de 1879 , diversos chefes pertencentes ao grupo parental consanguíneo dos Brondani se estabeleceram em terras próximas a comunidade de Vale Vêneto, inclusive o que havia solicitado ajuda por meio da carta acima apresentada. Entre as famílias Londero e Brondani - todas da comuna de Gemona do Friuli, província de Udine - se percebe a existência de uma rede parental estabelecida por casamento $^{8}$. A existência de vínculo de parentesco entre elas propiciou a solicitação de apoio financeiro para favorecer a transferência dos que

\footnotetext{
${ }^{6}$ Carta do padre Pedro Forgiarini ao imigrante Pedro Londero, 20 de novembro de 1878, Comuna de Gemona, Província de Udine (Righi, 2001, p. 464). Um primeiro casal do grupo dos Brondani, da comuna de Gemona, havia chegado à região colonial em janeiro de 1878, juntamente com outras famílias da península Itália.

${ }^{7} \mathrm{O}$ encaminhamento de cartas por parte dos imigrantes aos parentes na Itália era utilizado, principalmente, como recurso confiável para transmitir informações para aqueles que desejavam partir para o sul do Brasil. Sobre a importância desse recurso ver: Vendrame, 2010:2013.

${ }^{8}$ Os imigrantes Pedro Brondani e Domênico Daronco eram casados com mulheres que pertenciam ao grupo Londero, segundo indicações presente no quadro n. 4. Certamente, ambos receberam auxílio dos parentes e conhecidos que se encontravam na Colônia Silveira Martins.
} 
desejavam abandonar a localidade de origem. Foi prática recorrente a ocupação dos núcleos coloniais a partir de frentes de apoio composta por grupos de parentes ou conhecidos. Essa conduta demonstra o quanto as redes de auxílio foram usadas como mecanismo essencial para fornecer acomodação e integração entre os imigrantes nos núcleos coloniais. A assistência parental e aliança entre as famílias conferiam uma função agregativa que ditou as normas de distribuição da terra, de reprodução do grupo e organização da comunidade, ocupando, além disso, papel central na preservação dos valores e referenciais éticos ${ }^{9}$.

A existência de uma imigração espontânea foi percebida pelas autoridades imperiais brasileiras como um dos pontos decisivos no incremento do número de imigrantes no território nacional. Inicialmente, consideravam ser essa a resultante das campanhas realizadas na Europa pelos representantes do governo brasileiro, atribuindo, também, o aumento das expedições transoceânicas como fruto dos convites dos parentes e conterrâneos aqui domiciliados, capazes de mobilizar "centenas de imigrantes ao Brasil"10. Portanto, o aumento do número de imigrantes italianos chegando aos núcleos coloniais não pode ser compreendido sem levar em conta a manutenção dos vínculos que conectavam os indivíduos que haviam partido com aqueles que continuavam na pátria de origem.

Em relação a esse tipo de mobilidade autônoma, o conceito de cadeias migratórias tem se mostrado útil para compreender os caminhos abertos pelos indivíduos, suas características e os padrões de assentamento. Uma nova perspectiva de interpretação sobre a imigração italiana para o sul do Brasil é possível quando se passa a estudar o papel das mobilidades enquanto escolhas determinadas pelas relações sociais existentes entre as famílias, independentemente de se encontrarem em ambos os lados do Atlântico, permitindo, desse modo, uma série de ações coletivas, planejadas e comportamentos esperados entre os indivíduos (Grendi, 1978). Assim, os imigrantes passaram a ser percebidos como sujeitos ativos e responsáveis por articular as próprias transferências naquele momento específico. Os deslocamentos em cadeias indicam a existência de dinâmicas de gerenciamento da terra na Colônia Silveira Martins entre famílias fortemente ligadas por vínculos

\footnotetext{
${ }^{9}$ Ellen Woortmann $(1995,114-117)$ destaca o parentesco como fator determinante na definição das migrações, das identidades e das estratégias camponesas.

${ }^{10}$ Relatório da Comissão de internação dos imigrantes apresentado ao ministro e secretariado do estado dos negócios do Império, 31 de agosto de 1880. Diário oficial. Série Interior - Negócios de Províncias, IJJ1 - 779, Arquivo Nacional do Rio de Janeiro (ANRJ).
} 
sociais. Quando da chegada ao local de destino, as redes continuaram a desempenhar funções importantes na vida dos imigrantes como a integração do grupo, adaptação à sociedade receptora, na organização de instituições locais e na preservação de uma identidade coletiva ${ }^{11}$. Contudo, os vínculos transnacionais entre famílias foram, ao logo do processo migratório, perdendo-se. Quando da pesquisa etnográfica de Zanini (2006), na década passada, eram muito poucas as famílias que mantinham algum vínculo com parentes na Itália. Entre estas famílias, figuravam aquelas que haviam migrado nas primeiras décadas do século XX e por motivações como as acima expostas, de congregação famíliar.

\section{Formar a comunidade}

As famílias de imigrantes italianos que chegavam à Colônia Silveira Martins, a partir do final de 1877, recebiam do governo imperial um lote de terra, cuja extensão, na maior parte, era de vinte e dois hectares. O terreno deveria ser pago no decorrer de alguns anos com os rendimentos obtidos da produção agrícola, fruto do trabalho familiar na propriedade. Nessa primeira fase de ocupação da região colonial, muitas famílias requereram tanto um lote urbano, localizado no centro da sede da Colônia, como um rural, demonstrando, assim, o seu interesse em se dedicar não somente às atividades artesanais e comerciais, mas, também ao cultivo. ${ }^{12}$ Assim, sujeitos pertencentes à mesma unidade doméstica puderam investir em diferentes trabalhos para garantir a superação das dificuldades iniciais de adaptação e manutenção do grupo.

Na sede Silveira Martins, denominada inicialmente de Città Nuova, ao mesmo tempo em que eram demarcados os lotes e construídas as moradias dos imigrantes, foram surgindo as primeiras casas comerciais, administrativas, religiosas e também um espaço para abrigar temporariamente as novas famílias de estrangeiros que continuavam a chegar. Por ser o centro da Colônia, o local se caracterizava por uma maior circulação de pessoas e diversidade, abrigando imigrantes de diferentes regiões do Norte da Itália que passaram a desempenhar atividades profissionais variadas. Já na comunidade do Vale Vêneto,

\footnotetext{
${ }^{11}$ Paola Corti (1990) analisa as características diversas de duas comunidades mantidas por meio da experiência migratória de grupos parentais coesos internamente e vinculados aos conterrâneos. As duas cadeias migratórias conservaram a ligação com as "organizações políticas e reivindicatórias" da própria comunidade origem, permanecendo ancorados a esse local os valores identitários dos grupos.

${ }^{12}$ Relação dos lotes urbanos e rurais da sede da ex-Colônia Silveira Martins (Righi, 2001).
} 
localizada a seis quilômetros da sede, percebeu-se que a ocupação inicial se deu por um grupo de italianos que haviam partido da Província de Treviso, conforme se apresentou anteriormente neste artigo. Na referida localidade, o camponês Paulo Bortoluzzi adquiriu diversos lotes de terra, tornando-se um dos maiores imigrantes proprietários da Colônia ${ }^{13}$. Na colônia Silveira Martins, o imigrante Prospero Pippi, que se tornara comerciante, igualmente, representava aquele emigrado que veio ao Brasil com um determinado capital. Contudo, não se pode esquecer, como aponta Seyferth (1974), ao estudar a imigração alemã e italiana no Vale do Itajaí, o quanto os comerciantes (ou vendeiros) acumularam capital por meio das atividades de comércio. Nesta conversão do capital agrícola em capital comercial, em que os vendeiros pouco ou nada pagavam pelas mercadorias aos colonos, pois trabalhavam por meio da troca, foram se consolidando as primeiras elites das colônias ${ }^{14}$.

Porém, o que interessa analisar, a partir desse momento, é como determinadas iniciativas e inovações de lideranças da região colonial permitiram a agregação das famílias por meio da estruturação dos espaços sócio-religiosos e da fundação de associações. Também é importante perceber como alguns elementos simbólicos propiciaram a construção de uma identidade comunitária associativa. As elites camponesas locais foram protagonistas de ações que permitiram a formação de instituições agregativas, fundando, assim, um campo de direito, um espaço da vivência de rituais e de devoções.

Ao chegarem à região colonial, Bortoluzzi e outros imigrantes fundaram uma associação devocional para cultuar a São Francisco de Assis, construindo uma pequena capela em que foi colocada a imagem do santo trazida da Província de Treviso ${ }^{15}$. O local passou a atrair as famílias que haviam recebido lotes de terras próximas. Para garantir autonomia e certo status à comunidade que surgia, os principais chefes de família se organizaram para enviar um representante para a Itália a fim de encontrar padres que imigrassem para o sul do Brasil. Algum tempo depois, com a presença do padre italiano no povoado para a realização das atividades religiosas, a intenção dos imigrantes de fundar

\footnotetext{
${ }^{13}$ No registro de distribuição dos lotes coloniais, o imigrante Paulo Bortoluzzi aparece como beneficiário de sete lotes de terra $\left(\mathrm{n}^{\circ} 253,137,138,139,140,161,162\right)$ na comunidade do Vale Vêneto. A esposa Stella Furlan também recebeu um lote colonial $\left(\mathrm{n}^{\circ} 159\right)$ no mesmo lugar. Relação de distribuição dos lotes na Colônia Silveira Martins. In: Righi, 2001, p. 117, 182-183. Os lotes concedidos aos imigrantes italianos mediam aproximadamente 22 hectares.

${ }^{14} \mathrm{O}$ imigrante Paulo Bortoluzzi também acumulou capital material por meio das atividades comerciais entre a população colonial. Sobre essa questão ver; Vendrame, 2013.

${ }^{15}$ A pequena estátua de madeira de São Francisco de Assis se encontra no Museu de Vale Vêneto.
} 
uma localidade estava concretizada. Eles entendiam a presença de um sacerdote residente como indispensável para que pudessem reviver o "costume italiano". Para garantir a assistência religiosa, os italianos construíram uma casa para o sacerdote e passaram a lhe conferir um salário (Vendrame, 2007, p. 48-49).

Passados alguns anos, quando então o sacerdote Antônio Sório decidiu deixar a comunidade do Vale Vêneto, as lideranças locais, especialmente o imigrante Paulo Bortoluzzi, passaram a protestar contra aquele. Declaravam que não ficariam submissos à autoridade religiosa que não residisse entre eles. A saída de Sório, bem como a tentativa de continuar a administrar a capela a partir da paróquia de Silveira Martins, foi percebida como uma ameaça ao projeto de constituição de uma "localidade" autônoma, conforme se pode perceber nas queixas dos italianos:

Nós, abaixo-assinados, colonos residentes no núcleo próximo ao comércio do Sr. Paulo Bortoluzzi, recorremos a V. Exa. para torná-lo ciente de nossa situação (...) V. Exa. será informado que nos foi dado pelo governo um lote colonial gratuito para, sobre o mesmo, fundar uma localidade (...). Sobre esse lote construímos uma igreja de madeira e uma casa de alvenaria para a residência de um sacerdote. É uma iniciativa, diga-se de passagem, para informar que a localidade já começou e que promete um futuro brilhante. Aquele sacerdote, Pe. Antônio Sório, que veio da Itália por nossas custas e que morou aqui entre nós, na função de capelão, por aproximadamente três anos (...) teve que transferir sua residência para a sede [da Colônia Silveira Martins] (...) com soberba se revoltou contra nós e nos ameaçou de tornar-nos pequenos como um grão de mostarda, e que deveríamos ficar sob sua dependência e que ele é e será sempre o nosso pároco, querendo ou não querendo ${ }^{16}$.

A organização do espaço religioso - construção da igreja e presença do padre - era considerada fundamental no processo de constituição da localidade, sendo esse um direito que os imigrantes acreditavam possuir. Tais características eram sinais que a fundação do lugar já havia iniciado. No entanto, a autonomia se encontrava ameaçada devido à transferência de Antônio Sório para a sede da colônia. Esta era uma

\footnotetext{
${ }^{16}$ Carta dos fabriqueiros e moradores de Vale Vêneto ao presidente da província, 02 de dezembro de 1884. Comissão de Terras e Colonização (correspondência avulsa), Silveira Martins, maço 73, caixa 37, Arquivo Histórico do Rio Grande do Sul (AHRS).
} 
perda que não podiam aceitar. Por isso, as lideranças do Vale Vêneto enviaram um representante para a Itália para encontrar outros padres que desejassem se transferir para o Brasil meridional.

Durante o período em que a comunidade aguardava - entre 1885 e 1886 -, sem muitas certezas de que os padres viriam, os imigrantes Paulo Bortoluzzi e Luis Rosso escreveram ao superior geral da Pia Sociedade das Missões - ordem religiosa dos padres palotinos -, em Roma, relatando suas "desgraças, suspiros e aborrecimentos no ramo espiritual. [Tudo isso era] Grave para uma pequena população italiana e católica, que se encontrava no Brasil". Quando se referiam ao atendimento dispensado à comunidade por um "sacerdote brasileiro", reclamaram alegando que esse somente realizava batizados e matrimônios. Assim, entendiam que as atividades religiosas ficavam prejudicadas pelo fato de não poderem cumprir os sacramentos da confissão e comunhão, ressaltando a necessidade de um padre que atendesse aos seus costumes de imigrantes "italianos e católicos"17. O desejo pelo atendimento espiritual por sacerdotes que tivessem vindo da Itália, sendo esses conhecedores dos costumes religiosos dos imigrantes, era apresentado como indispensável.

Em 1886, dois sacerdotes palotinos fixaram residência no Vale Vêneto. A seguir, tanto a devoção a São Francisco como a associação leiga que administrava a capela foram extintas, sendo edificada uma nova igreja em substituição à existente que foi consagrada ao Santíssimo Sacramento. Tais mudanças receberam apoio da população, pois, assim, a comunidade caminhava rumo ao progresso religioso, social, econômico e à elevação do próprio status (Vendrame, 2007, p. 67). O imigrante Paulo Bortoluzzi vendeu pequenas dimensões de terras aos padres e realizou empréstimos financeiros aos $\operatorname{mesmos}^{18}$. Posteriormente, concedeu uma casa para a instalação das irmãs do Sagrado Coração de Maria, em 1892. As religiosas abriram um pequeno colégio que, em breve, se transformaria num internato. Os padres palotinos também passaram a se dedicar a educação religiosa dos filhos dos imigrantes (Bonfada, 1989, p. 60-61).

Não se deve negar o fato de Bortoluzzi ser católico fervoroso e estar preocupado com a vivência dos costumes italianos, mas, ao mesmo tempo, havia interesse pessoal de tornar o Vale Vêneto uma localidade

\footnotetext{
${ }^{17}$ Carta de Paulo Bortoluzzi e Luiz Rosso ao procurador geral da Pia Sociedade das Missões, Guilherme Whitmee, [18--]. In: Righi, 2001, p. 360-63.

${ }^{18}$ Escritura de venda realizada por Paulo Bortoluzzi aos padres, 21 de outubro de 1886. Caixa 3, Missão Brasileira, Arquivo Histórico Nossa Senhora Conquistadora (AHNSC), Santa Maria.
} 
próspera, referência na região colonial. Porém, para isso acontecer, era necessário favorecer a instalação de congregações religiosas, segundo pensamento dele. Havia, naquele período, uma disputa entre a sede da Colônia Silveira Martins, considerada mais maçônica e Vale Veneto, que pretendia ser um local católico (Véscio, 2001). Além disso, o referido imigrante também estava trabalhando para consolidar seu próprio prestígio e aumentar a influência política e comercial entre os conterrâneos. Bortoluzzi, antes mesmo de sair da Itália, havia expressado o desejo de ser chefe de uma Colônia no Brasil, assim, logo que chegou buscou se firmar enquanto liderança local através da fundação de um templo e cerimônias locais.

Foi, partindo das bases religiosas, da participação em celebrações comuns, do cumprimento dos sacramentos e da renovação dos vínculos de afinidades e parentesco, por meio dos rituais de batismo e casamento, que as famílias se identificavam como pertencentes à comunidade. Nesse sentido, a localidade surge da própria vontade dos habitantes de fundar um espaço de culto e de identificação comum. As práticas cerimoniais permitem a afirmação da existência da comunidade, de um espaço de direito e deveres, da expressão de uma cultura e de identidade. Ignorar a maneira como eram tomadas as decisões referentes à vida na paróquia é descuidar de uma das dimensões mais significativas do processo de constituição de um lugar: o modo como os atores sociais pensavam e agiam no mundo no qual se encontravam inseridos. A localidade é um espaço territorial de "práticas co-divididas", caracterizando-se enquanto construção cultural e social fruto da produção contínua por parte dos próprios habitantes, segundo destaca Angelo Torre (2011, p. 214). Os imigrantes desejam ter, ao seu redor, um mundo compatível ao que haviam deixado na Itália e, para isto, determinadas simbologias e práticas necessitam ser mantidas, bem como a formação de uma paisagem cultural partilhada.

\section{O poder do pároco}

Além da família e das associações religiosas, a parentela também aparece como instância agregativa na esfera local. O fortalecimento e ampliação das redes parentais, por meio da prática de apadrinhamento, surgem como um dos campos de atuação do jovem sacerdote italiano Antônio Sório. Assim que se transferiu da comunidade de Vale Vêneto para a sede da Colônia Silveira Martins, em 1884, a fim de coordenar a recém-instituída paróquia, padre Sório compareceu na Pia Batismal 
como padrinho dos filhos dos imigrantes italianos. Essa atitude permitiu a criação de laços de afinidades e aliança com os conterrâneos. Durante os quinze anos em que permaneceu na condição de pároco (1884-1899), Antônio Sório surgiu trinta e sete vezes como padrinho direto. Esse desempenho permitiu que o mesmo mantivesse certo controle sobre a vida religiosa, social e política na paróquia. Estes compadrios, com certeza, favoreceram sua permanência na paróquia, apesar da existência de oposições locais (Vendrame, 2013).

Os vínculos construídos, ou apenas reforçados, na pia batismal foram responsáveis por estabelecer uma rede parental para além dos laços de sangue, favorecendo, em diversas situações, a circulação de auxílios e benefícios mútuos entre os indivíduos aparentados (Xavier e Hespanha, 1993). A formação desse tipo de ligação ajuda a pensar sobre as escolhas dos imigrantes para garantir a construção de prestígio, a formação de redes de interdependências, afinidades e a manutenção de cultura corporativa que permitiram uma melhor acomodação e identificação nos núcleos coloniais. Enquanto autoridade religiosa entre os conterrâneos, António Sório assumiu a função de agente consular. Para além das atividades de pároco, Sório passou a orientar a população em questões relacionadas ao retorno à pátria de origem. Utilizava o momento das prédicas, no púlpito da igreja, para esclarecer a população sobre as possibilidades de regresso para a península itálica e vantagens que poderiam ser obtidas do governo italiano ${ }^{19}$.

Além disso, enquanto representante da pátria de origem na região colonial, Antônio Sório também era convocado para fornecer conselhos, apaziguar disputas internas nas comunidades e encaminhar demandas da população às instâncias externas de poder. Enfim, havia conquistado a posição de autoridade na ex-Colônia Silveira Martins, sendo entendido como defensor e emissário dos imigrantes frente a municipalidade de Santa Maria $^{20}$. Agentes consulares, como o referido padre, faziam a ligação das famílias camponesas residentes nos afastados núcleos de colonização do Rio Grande do Sul e o consulado italiano, localizado na capital do Estado. Segundo declaração do próprio Sório, “a chamado do cônsul d'Itália, estou abertamente servindo ao meu pátrio governo como cidadão, e como sacerdote aos meus paroquianos e conacionais". Assim, como agente consular, tinha "a obrigação de visitar as escolas

\footnotetext{
${ }^{19}$ Carta de Antônio Basso, abril de 1889, Silveira Martins (Righi, 2001, p. 455, 470).

${ }^{20}$ A Colônia Silveira Martins passou a ser denominada de ex-Colônia em 1882, quando emancipouse da condição de colônia imperial, tornando-se, posteriormente, quarto distrito do município de Santa Maria.
} 
italianas existentes nesta ex-Colônia, das quais oito são auxiliadas pelo governo do Rei Humberto, e mais algumas privadas ou particulares (...)", conforme declarou o próprio padre ${ }^{21}$. Não se pode esquecer, igualmente, o importante papel que os padres desempenhavam em diferentes frentes entre os colonos italianos (Vendrame, 2007), ocupando papéis muitas vezes mitificados, como ressalta Merlotti (1979).

No centro da paróquia de Silveira Martins, Antônio Sório havia patrocinado a abertura de uma "escola pública", assistida pelos recursos do governo italiano, na qual a sobrinha Mariana atuava como professora $^{22}$. Além de supervisionar o trabalho nas escolas, também aparece participando do mercado da terra, vendendo bens de alguns imigrantes que lhe depositavam confiança e resgatando quantias de dinheiro nos bancos e consulado, localizados na capital Porto Alegre ${ }^{23}$. Enquanto pároco da sede, empenhou-se na construção da igreja matriz, apoiou a edificação de diversas capelas, conduzindo uma política centralista em relação aos diversos povoados dependentes. Essas iniciativas garantiram a agregação em torno da freguesia de Silveira Martins e, consequentemente, viabilizaram a construção do território da localidade, com seus símbolos e vínculos. Para Ângelo Torre (2011, p. 211, 383-390), a localidade, enquanto resultado de um processo de produção do lugar, corresponde às exigências de dar voz pública às instâncias associativas de indivíduos, grupos de parentes e aliados. Assim, o espaço do sagrado, dos rituais comunitários e outros ambientes de privilégios eram recursos utilizados para garantir a legitimidade sobre o território frente a grupos externos concorrentes.

A existência de alianças e interesses compartilhados entre os indivíduos que faziam parte das agregações locais garantiram o sucesso das ações de sujeitos particulares. Tudo isso favorecia o surgimento de uma organização política que legitimava a ocupação como processo de constituição de uma configuração social e comunitária. Nesse sentido, é importante analisar não apenas o conteúdo de alguns discursos presentes nas fontes documentais, mas, especialmente, a intencionalidade que cada ação expressa. Ou seja, chama-se a atenção para a questão da verificação das pretensões dos atores sociais ao agirem de determinada maneira.

\footnotetext{
${ }^{21}$ Carta do padre Antônio Sório, agente oficioso do Régio Cônsul da Itália, "A pedidos. Resposta a um caluniador". Jornal O Combatente, 22 de outubro de 1893, Santa Maria. Arquivo Casa de Memória Edmundo Cardoso (ACMEC).

${ }^{22}$ Testamento de Antônio Sório, Provedoria de Santa Maria, no 116, maço 3, ano 1900, Arquivo Público do Rio Grande do Sul (APERS).

${ }^{23}$ Procurações. Santa Maria (4º distrito). Livro 01, 02.11 .1896 - 07.03.1901, APERS.
} 
Em relação ao padre Sório, observou-se que, em 1885, na comunidade de Silveira Martins, ele surge como fundador de uma sociedade dos operários "Umberto I". Essa associação reuniu, em 1896, um total de cinquenta e seis membros associados que tinha por objetivo fornecer auxílio aos sócios nos casos de doenças, enfermidades e velhice. Também deveria promover a segurança, a solidariedade, encorajar a "classe operária" ao trabalho e à poupança. Os associados eram indivíduos que trabalhavam na pequena indústria, comércio e na agricultura. A sociedade de mútuo socorro possuía um conselho administrativo composto por "chefes-sessão" que deviam vigiar a conduta dos sócios, cuidar do cumprimento dos deveres, harmonizar discórdias e verificar as necessidades dos doentes. ${ }^{24}$

O pároco Antônio Sório passou a ocupar o cargo de presidente da referida associação, elaborando, juntamente como outros conterrâneos, o regulamento de funcionamento da mesma. Logo, esse tipo de iniciativa evidencia a constituição de um poder autônomo, autorregulador, para reger e controlar o comportamento dos imigrantes na comunidade. Os indivíduos membros da "Umberto I" também podiam fazer parte de outras corporações, como aquelas ligadas diretamente à igreja. Nas comunidades camponesas, tanto a paróquia quanto as confrarias leigas podiam ser administradas por um tipo de configuração parental, caracterizando, dessa maneira, um modelo de estrutura política de eficácia local (Grendi, 1993).

A presença do pároco frente à associação dos “operários italianos de Silveira Martins" demonstra a ligação entre as esferas sagrada, assistencial e política que se estruturaram a partir de uma área de pertencimento comum. Nas regiões coloniais, as sociedades de mútuo socorro, na maioria das vezes, recebiam o nome de algum herói que havia participado da Unificação da Itália e membros da família real. E, como tantas outras, a sociedade dos operários "Umberto I" também era responsável por promover festividades e comemorações em datas nacionais, cultuar a memória dos heróis e integrantes da Casa Real italiana.

Apesar da associação dos operários italianos não estar ligada a questões sócio-religiosas foi a paróquia que forneceu as bases para a criação da mesma. Porém, o contrário também podia ocorrer, e, nessa situação, seriam as associações laicas a fornecer as bases de

${ }^{24}$ Statuto dell'Associazione di Mutuo Soccorso fra gli operai italiani di Silveira Martins, 1897, p. 3. Caixa Silveira Martins, Centro de Pesquisas Genealógicas, Nova Palma (CPG-NP). 
sustentação para o surgimento de uma paróquia (Grendi, 1993). Em ambos os espaços era praticada a ação política individual e familiar, eram reforçadas as redes interpessoais, estabelecidas as interações, as trocas de apoios e, por fim, percebidas pelos atores sociais as afinidades. Muitas casas de Mutuo-Socorro italianas no Rio Grande do Sul terão, entre seus fundadores, membros da maçonaria e serão estes, por um longo período, que empreenderão atividades de cooperação e assistência e, posteriormente, no governo fascista de Mussolini, promoverão a italianitá.

Desse modo, entende-se que a estrutura da comunidade, assentada sobre ritos, normas e associações, manifestava uma forma de governo local singular que se apresentava como uma barreira frente às pressões das instituições públicas externas. O papel de Sório foi fundamental na constituição de coesão entre os imigrantes italianos, principalmente enquanto estratégia para fazer circular recursos e apoios. Como se ressaltou acima, o mesmo também surgiu como incentivador da promoção de festividades e comemorações que mantinham vivas a ligação do grupo com a pátria deixada. Além disso, apoiou a abertura de diversas escolas subvencionadas pelo governo italiano na região colonial, logo, o culto a símbolos e heróis italianos também foram reverenciados em tais espaços. No cotidiano das comunidades, os desempenhos de alguns indivíduos, ou ainda de um grupo, visavam manter vivo o sentimento de italianidade por meio de manifestações sócio-culturais. Especialmente no caso de Antônio Sório, sua participação na formação de bases de assistência, de cooperação e identificação entre os conterrâneos, resultou na conquista de posição de prestígio e poder político.

\section{Conflitos locais}

Nesta última parte do artigo, serão apresentados alguns episódios de conflitos ocorridos nos núcleos coloniais entre imigrantes italianos e os nativos, denominados de "brasileiros". Importante salientar que a categoria brasileiro englobava nativos, moradores que já estavam na região, bem como as populações de cor, os negros que, quando da chegada dos imigrantes, ainda estavam sob o regime escravocrata. Busca-se perceber, por meio das falas dos sujeitos, as justificativas usadas para o estabelecimento de uma diferenciação entre aqueles. Apesar das disputas interétnicas não serem o objetivo principal deste artigo, elas permitem perceber qual era a compreensão dos italianos em relação ao espaço que abrangia a Colônia. Ou ainda, como, por meio de 
atitudes que demonstravam a questão da superioridade, geralmente por meio de práticas violentas, os habitantes desenvolviam e reforçavam uma consciência social de direito sobre o lugar. Mediante documentação judicial - processos-crime - percebe-se como os atores reivindicavam direitos na constituição das comunidades. Muito além do discurso, são as pequenas ações que ajudam a compreender a questão do pertencimento ou da diferenciação, sendo elas inseparáveis dos lugares em que foram concebidas.

Em 1901, após participarem de uma celebração religiosa, várias pessoas se encontravam reunidas na casa de comércio do imigrante Vicente Pigatto, localizada em Faxinal do Soturno, quando "alguns italianos" apareceram armados de "porretes" em atitude provocativa contra os "brasileiros" que lá estavam. Dentre esses se encontrava Celestino Ribeiro dos Santos, que declarou aos presentes "que em dia de festa não havia necessidade de andarem armados", ouvindo como resposta que era "melhor ficar quieto porque negro ali não falava". Diante desta troca de palavras, teve início o conflito, e um dos italianos "vibrou com uma cacetada na cabeça de Celestino", deixando-o "caído por terra". Em seguida, na tentativa de socorrer o irmão, Rodolfo Ribeiro dos Santos foi "barbaramente espancando" pelo grupo, resultando em sua morte. ${ }^{25}$ De acordo com informações colhidas entre as testemunhas, cinco italianos esbordoaram a cacetetes os irmãos dos Santos. Apesar disso, um depoente afirmou que "não sabe o que determinou o conflito, mas que tem ciência de que os italianos, ao reunirem-se, tinham a intenção de maltratar os brasileiros. Acrescenta ser "praxe neste distrito [ $5^{\circ}$ distrito de Cachoeira do Sul] os italianos armarem-se" para atacar os nacionais ${ }^{26}$.

Os conflitos entre italianos e negros, visualizados, principalmente, em espancamentos coletivos em locais públicos, apresentam-se como uma maneira dos primeiros buscarem impor seu controle e domínio nas comunidades rurais. Analisando as relações de convivência entre aqueles grupos, Karl Monsma (2007, p. 115) afirma que as tensões se constituem em embates cotidianos para ver quem tinha o direito de mandar e quem devia obedecer. Quando um imigrante feria ou matava um "brasileiro", geralmente isso ocorria após esse ter afirmado "sua igualdade e dignidade abertamente". As agressões contrárias ocorriam como resposta a uma

\footnotetext{
${ }^{25} \mathrm{O}$ brasileiro Rodolfo dos Santos aparece, em 1900, prestando serviços temporários para as famílias imigrantes na região colonial. Livro caixa da casa de comércio de Guilherme Kettermann, 08.05.1899 a 10.11.1901, nº 1, Acervo Particular Família Melo, Faxinal do Soturno.

${ }^{26}$ Processo-crime, Cartório Cível e Crime, Cachoeira do Sul, nº 3487, Maço 26, 1901. APERS.
} 
atitude de superioridade e autoridade, momento esse em que o oponente se recusava em aceitar a humilhação e a subordinação a ele imposta. Nesse caso, as reivindicações por respeito e igualdade eram percebidas pelos italianos como ameaças à sua identidade, posição e honra.

Mesmo que os imigrantes e os nacionais residissem em uma mesma região colonial, aqueles procuraram manter uma diferenciação mediante exclusão do outro. De fato não havia condição de igualdade entre eles. A manutenção da fronteira entre os indivíduos, para além da questão da cor, tinha eficiência porque os italianos haviam recebido privilégios, como o acesso facilitado a terra para estabelecimento das famílias, constituição de comunidades e vivências das práticas sócio-religiosas. Portanto, ao reagirem com violência às atitudes ou às palavras dos "negros", os imigrantes demonstravam que não aceitavam aqueles como iguais, procurando de tal modo demarcar a superioridade e prestígio em relação aos outros.

Nas regiões de colonização italiana no Rio Grande do Sul, os imigrantes foram se organizando a partir da mobilização em construir capelas, escolher os santos padroeiros, garantir a assistência de um sacerdote, fundar associações e reforçar laços, colocando os indivíduos em relações de reciprocidades. Tudo isso foi permitindo a formação da localidade enquanto um espaço de práticas sociais e culturais corporativas e compartilhadas. É também das tensões internas entre os grupos que habitam em determinado núcleos que nasce a necessidade de fundar locais de culto e sociabilidade, legitimando, muitas vezes, através de confrontos com outros o direito que possuem sobre um território.

Geralmente, próximos aos edifícios religiosos surgiram casas de comércio, locais em que a população promovia pequenos bailes e outros divertimentos, revivendo as antigas tradições e estabelecendo formas de sociabilidade. Era comum, em tais ocasiões, os italianos optarem por manifestar superioridade punindo aqueles que, de algum modo, assumiam comportamento afrontoso ou os classificavam por denominações consideradas ofensivas. Trata-se de compreender, igualmente, as questões de defesa da honra, como comum em grupos camponeses. Foi reagindo contra o epíteto de "gringo", pronunciado por Alexandre Alves de Oliveira, que o imigrante João Vallandro (24 anos, casado, carpinteiro) sacou a pistola e disparou contra o ofensor. Em seu auxílio, apresentaram-se diversos patrícios tanto no momento do conflito, atirando tijolos sobre a vítima e seu companheiro, quanto posteriormente, ao protegerem o investigado das malhas da justiça. Os italianos acharam afrontoso um "brasileiro" entrar na casa de 
negócio armado de facão pronunciando palavras de ameaça ao réu. ${ }^{27}$ Ao demonstrarem solidariedade aos patrícios, indicaram a existência de determinados deveres entre as famílias locais, compromissos esses fundamentais para garantir o ajustamento à nova realidade. Também era o momento de demarcação dos limites relacionais com outros grupos étnicos. O sentimento de pertencimento se construía por meio dos vínculos entre as famílias, proximidade territorial e a participação nas atividades sócio-religiosas. A legitimidade de um poder local, bem como o processo de acomodação, se concretizava através de práticas solidárias e a vivência de uma determinada cultura comunitária (Vendrame, 2013).

A aprovação do uso de violência física contra certas pessoas pode ser analisada pelas declarações de um dos espancados: "muitos italianos ali residentes aprovaram [as agressões] dizendo ser preciso eliminar todos os brasileiros residentes na colônia, pois ela havia sido criada apenas para eles" 28 . Como se percebe, os núcleos coloniais eram entendidos pelos imigrantes como espaços que deviam ser geridos pelas normas e princípios de seus principais ocupantes. Desse modo, a explicação evidencia questões importantes, como as fronteiras étnicas e sociais demarcadas por meio da prática cotidiana entre os grupos ${ }^{29}$. As tensões e violências aparecem, aqui, como mecanismos válidos para demarcar o privilégio e o direito dos imigrantes em relação ao espaço destinado à colonização italiana no Rio Grande do Sul. Nesse sentido, a identidade do grupo surge da ideia de que a eles camponeses havia sido destinado à terras existentes na região colonial, e sobre elas tinham direito de fundar um ambiente de convivência que permitisse a sociabilidade e a constituição de relações de reciprocidade endógenas.

As comunidades se constituíram, assim, por meio das cerimônias e do patrimônio imaterial e suas simbologias que ligavam as famílias aparentadas e vizinhas, procurando minimizar as tensões internas, e apesar das práticas de diferenciação que os grupos de indivíduos passaram a estabelecer entre si. Frente à incerteza com relação à adaptação e o sucesso dos projetos individuais e coletivos, foi o reforço das redes de relações no território de adoção que permitiu a concretização dos planos trazidos do além-mar e possibilitou a construção de uma identidade

\footnotetext{
${ }^{27}$ Processo-crime, Cartório cível e Crime, Santa Maria, n 1145, Maço 35, 1890. APERS.

${ }^{28}$ Processo-crime, Cível e crime, Caxias do Sul, no 1039, Maço 35, 1900, APERS.

${ }^{29} \mathrm{~A}$ identidade étnica, como qualquer outra identidade coletiva, é percebida através de uma concepção dinâmica, uma vez que ela se constitui e se transforma pela interação de grupos sociais em processos contínuos "de exclusão e inclusão que estabelecem limites entre tais grupos, definindo os que integram ou não" (Barth, 2000; Poutignat e Streiff-Fenart, 2007, p. 11).
} 
que também se fez em oposição aos nativos brasileiros, na condição de colonizadores e pioneiros.

\section{Referências}

BAILY, Samuel L. Cadenas migratórias de italianos a la Argentina: algunos comentarios. Studios migratórios, v. 3, n. 8, p. 125-135, 1988.

BARTH, Frederik. O guru, o iniciador e outras variações antropológicas. Rio de Janeiro: Contracapa, 2002. p. 243.

BONFADA, Genésio. Os palotinos no Rio Grande do Sul. Santa Maria: Pallotti, 1991. p. 235.

BURMANN, Francisco. Memórias do Pe. Francisco Burmann. 1910. Caixa 2, Missão Brasileira. AHNSC, Santa Maria.

CORTI, Paola. Identità e comunità d'origine nelle vechie e nelle nuove generazioni di emigranti: due paesi, due storie familiari. In: ROSOLI, G. et al. Identità e integrazione: famiglie e paesi, percorsi e immagini di sè nell' emigrazione Biellese. Milano: Electa, 1990. p. 123-174.

CERETTA, Antônio. História do Vale Vêneto (1877-1886). 1894, Caixa 4, Missão Brasileira, Arquivo Histórico Nossa Senhora Conquistadora, Santa Maria.

DEVOTO, Fernando. Las cadenas migratórias italianas: algumas reflexiones a la luz del caso argentino. In: Studi Emigrazione, v. XXIV, n. 87, p. 355-373, 1987.

GRENDI, Edoardo. Polanyi: dall' antropologia economica alla microanalise storica. Milão: Etas libri, 1978. p. 179.

GRENDI, Edoardo. Il Cervo e la republica. Il modello lìgure di antico regime. Torino: Giulio Einaudi Editore, 1993. p. 202.

LORENZONI, Júlio. Memórias de um imigrante. Porto Alegre: Sulina, 1975. p. 264.

MACIEL, Maria Lucia. O milagre italiano: caos, crise e criatividade. Rio de Janeiro: Relume Dumará/Brasília: Paralelo 15 Editores, 1996. p. 230.

MERLOTTI, Vânia B. P. O mito do padre entre descendentes italianos. Porto Alegre, EST; Caxias do Sul: UCS, 1979. p. 103.

MIGUEZ, E. Microhistoria, redes sociales e historia de las migraciones: ideas sugestivas y fuentes parcas. In: BJERG, M.; OTERO, H. (Comp.). Inmigracion y redes sociales en la Argentina Moderna. Tandil: CEMA-IEHS, 1995. p. 23-33.

POTIGNAUT, P.; STREIFF-FENART, J. Teorias da etnicidade: seguido de grupos étnicos e suas fronteiras de Frederik Barth. Tradução de E. Fernandes. São Paulo: UNESP, 1997. p. 250.

RAMELLA, Franco. Mobilidad geográfica y mobilidad social. Notas sobre la emigración rural de la Itália del Noroeste (1880-1914). Estudios Migratórios Latinoamericanos, v. 6, n. 17, p. 107-118, 1991.

RAMELLA, Franco. Por um uso fuerto del concepto de red em los estudios migratórios. In: BJERG, M.; OTERO, H. (Comp.). Inmigracion y redes sociales en la Argentina Moderna. Tandil CEMLA-IEHS, 1995. p. 9-21.

RIGHI, José V.; BISOGNIN, Edir L.; TORRI, Valmor. Povoadores da Quarta Colônia. Porto Alegre: EST, 2001. p. 696. 
TORRE, Angelo. Luoghi: La produzione di località in età moderna e contemporanea. Roma: Donzelli Editore, 2011.p. 407.

SEYFERTH, Giralda. A colonização alemã no Vale do Itajaí-Mirim. Porto Alegre: Editora Movimento, 1974.

VENDRAME, Maíra Ines. "Lá éramos servos, aqui somos senhores”: a organização dos imigrantes italianos na ex-colônia Silveira Martins (1877-1914). Santa Maria: Ed. da UFSM, 2007. p. 321.

VENDRAME, Maíra Ines. Nós partimos pelo mundo, mas para viver melhor: redes sociais, família e estratégias migratórias. In: Revista Métis, v. 9, n. 17, p. 69-82, 2010.

VENDRAME, Maíra Ines. Ares de vingança: redes sociais, honra familiar e práticas de justiça entre os imigrantes italianos no sul do Brasil (1878-1910). Tese (Doutorado) - Faculdade de Filosofia e Ciências Humanas, Pontifícia Universidade Católica do Rio Grande do Sul, Porto Alegre, 2013. p. 478.

XAVIER, Angela; HESPANHA, Antonio Manuel. As redes clientelares. In: HESPANHA, Antonio Manuel (Coord.). História de Portugal - Antigo Regime. Lisboa: Editoral Estampa, 1993. v. 4. p. 381-394.

VÉSCIO, Luiz E. O Crime do Padre Sório: Maçonaria e Igreja Católica no Rio Grande do Sul (1893-1925). Porto Alegre: Editora da UFRGS; Santa Maria: Editora da UFSM, 2001. p. 327.

WOORTMANN, Ellen. Herdeiros, parentes e compadres: colonos do sul e sitiantes do nordeste. São Paulo: HUCITEC; Brasília: Edunb, 1995. p. 336.

ZANINI, Maria Catarina. Italianidade no Brasil meridional. A construção da identidade étnica na região de Santa Maria-RS. Santa Maria: Ed. da UFSM, 2006. p. 278.

ZANINI, Maria Catarina. Pertencimento étnico e territorialidade: italianos na região central do Rio Grande do Sul (BRASIL). Redes (Santa Cruz do Sul), v. 13, p. 140-163, 2008 . 